\title{
SAGITTAL BALANCE IN ADOLESCENT IDIOPATHIC SCOLIOSIS
}

\author{
BALANÇO SAGITAL NA ESCOLIOSE IDIOPÁTICA DO ADOLESCENTE \\ BALANCE SAGITAL EN LA ESCOLIOSIS IDIOPÁTICA ADOLESCENTE
}

Eduardo Moreira Pinto, ${ }^{1}$ Jorge Alves, ${ }^{2}$ Artur Telxelra, ${ }^{1}$ António Miranda ${ }^{1}$

1. Entre Douro e Vouga Hospital Center, Orthopaedic Surgery and Traumatology Division, Santa Maria da Feira, Portugal.

2. Tâmega e Sousa Hospital Center, Orthopaedic Surgery and Traumatology Division, Penafiel, Portugal.

\begin{abstract}
Objective: The objective of this study is to achieve a better understanding of the parameters that influence sagittal balance in a population with adolescent idiopathic scoliosis (AIS). Methods: A retrospective study of 80 patients with adolescent idiopathic scoliosis (AIS) was conducted. The parameters evaluated were: age, sex, pelvic incidence (PI), sacral slop (SS), pelvic tilt (PT), sagittal balance (SB), coronal balance (CB), lumbar lordosis (LL), thoracic kyphosis (TK) divided into upper (between T1 and T5) and lower (between T5 and T12), cervical spine alignment (CSA), and Cobb's coronal angle (CCA) of primary scoliotic curvature. Results: Regarding the sagittal balance, this study demonstrated a significant statistical positive correlation with cervical shape $(p<0.01)$ and upper thoracic kyphosis (from $T 1$ to T5) $(p<0.05)$, but not with the other variables. LL had a strong influence on lower thoracic curvature (from T5 to T12) and was strongly influenced by the PI and SS. Conclusions: Sagittal balance is a parameter that is influenced by multiple factors. In fact, it is closely related to cervical shape and the upper thoracic curvature (from T1 to T5), which in turn, is closely linked to the severity of the scoliotic kyphosis. The Cobb angle of the lower thoracic spine (from T5 to T12) is more closely correlated with the angle of lumbar lordosis than with the upper thoracic kyphosis (from T1 to T5). Level of evidence IV; Case Series.
\end{abstract}

Keywords: Scoliosis; Spine; Kyphosis; Adolescent.

\section{RESUMO}

Objetivo: O objetivo deste estudo é obter uma melhor compreensão dos parâmetros que influenciam o equilíbrio sagital em uma população com escoliose idiopática do adolescente (AIS). Métodos: Foi realizado um estudo retrospectivo de 80 pacientes com escoliose idiopática do adolescente (AIS). Os parâmetros avaliados foram: idade, sexo, incidência pélvica (PI), sacral slope (SS), pelvic tilt (PT), equilíbrio sagital (SB), balanço coronal (CB), lordose lombar (LL), cifose torácica (TK) dividida em alta (entre T1 e T5) e baixa (entre T5 e T12), alinhamento da coluna cervical (CSA) e ângulo de Cobb coronal de curvatura escoliótica principal (CCA). Resultados: Em relação ao equilíbrio sagital, demonstrou-se uma correlação positiva significativamente estatística com o formato da coluna cervical ( $p<0,01)$ e com o ângulo de cifose da porção superior da coluna torácica (de T1 para T5) ( $p<0,05)$, mas não com as demais variáveis. A LL exerce uma forte influência sobre a porção inferior da curvatura torácica (de T5 a T12) e é fortemente influenciada pela PI e SS. Conclusões: O equilíbrio sagital é um parâmetro influenciado por múltiplos fatores. De fato, está extremamente relacionado com o formato da coluna cervical e com a coluna torácica superior (de T1 a T5) que, por sua vez, apresenta uma simbiose com a gravidade da curvatura escoliótica. O ângulo de Cobb da porção inferior da coluna torácica (de T5 a T12) apresenta uma relação maior com o ângulo da lordose lombar do que com a curvatura torácica superior (de T1 a T5). Nível de evidência IV; Série de Casos.

Descritores: Escoliose; Coluna Vertebral; Cifose; Adolescente.

\section{RESUMEN}

Objetivo: El objetivo de este estudio es lograr una mejor comprensión de los parámetros que influyen en el equilibrio sagital en una población con escoliosis idiopática del adolescente (EIA). Métodos: Se realizó un estudio retrospectivo de 80 pacientes con escoliosis idiopática del adolescente (EIA). Los parámetros evaluados fueron: edad, sexo, incidencia pélvica (IP), inclinación sacra (IS), inclinación pélvica (InP), balance sagital (BS), balance coronal (BC), lordosis lumbar (LL), cifosis torácica (CT) divididos en alta (entre T1 y T5) y baja (entre T5 y T12), alineación de la columna cervical (AC) y ángulo coronal de Cobb (ACC) de curvatura escoliótica primaria. Resultados: Con respecto al balance sagital, este estudio demostró una correlación positiva estadísticamente significativa con la forma cervical ( $p<$ $0,01$ ) y cifosis de la porción superior de la columna (de T1 a T5) ( $p<0,05)$, pero no con las otras variables. LL tuvo una fuerte influencia en la parte inferior de la curvatura torácica (de T5 a T12) y fue fuertemente influenciada por la IP y la IS. Conclusiones: El balance sagital es un parámetro influenciado por múltiples factores. De hecho, está estrechamente relacionado con la forma cervical y la curvatura torácica superior (de T1 a T5), que a su vez, está estrechamente relacionada con la gravedad de la cifosis escoliótica. El ángulo de Cobb de la porción inferior de la columna torácica (de T5 a T12) presenta mayor relación con el ángulo de lordosis lumbar que con la cifosis torácica superior (de T1 a T5). Nivel de evidencia IV; Serie de Casos.

Descriptores: Escoliosis; Columna Vertebral; Cifosis; Adolescente. 


\section{INTRODUCTION}

The human standing posture involves a delicate balance between the spine and the pelvis. Although all primates are able to place themselves in the orthostatic position, Homo sapiens is the only able to travel long distances and steadily in this way. ${ }^{1}$ The reason for this occurrence is that humans have a unique lumbar lordotic curvature. A balanced posture is obtained when these body segments are aligned in a way that minimizes energy expenditure. ${ }^{2-4}$ The importance of sagittal spinopelvic organization in spine pathology, and the crucial need to restore it after surgical treatment, are now recognized in the literature. ${ }^{5}$

Some authors have reported the normal values of sagittal spinal curves in children and adolescents. ${ }^{6,7}$ Other studies have also characterized the pelvic orientation and morphology in the sagittal plane of paediatric subjects. ${ }^{8,9}$ Upasani et al. presented a relation between lumbar spine lordosis and pelvic geometry. Effectively, the lumbar spine has a close relationship with the pelvic orientation, expressed in particular by the sacral slope, which is influenced by the pelvic incidence (PI). ${ }^{10}$ The sagittal curvature of the spine and the pelvic balance swing together to maintain a stable posture and horizontal gaze. Once this sagittal alignment is lost, more energy is needed for the body to remain balanced without any external support. ${ }^{11}$ The pelvic incidence is unique in each individual, and is independent of the spatial alignment of the pelvis. Therefore, it reflects the anatomy of the pelvis and does not modify with changes in pelvic or spinal position. ${ }^{12-16}$ Several studies have shown that $\mathrm{PI}$ is closely related to the sacral slope (SS) and pelvic tilt (PT), and that it remains relatively constant during childhood. It increases significantly during adolescence, reaching its maximum value in adulthood. ${ }^{17}$ Others defend the view that there is no correlation between the PT and SS in patients with AIS.

Idiopathic scoliosis is a three-dimensional deformity of the torso consisting of lateral curvature of the spine and vertebral rotation. ${ }^{18}$ Satisfactory treatment for AIS includes maximum correction in the coronal plane, in addition to adequate restoration of the sagittal spinal alignment and vertebral rotation. Many studies ${ }^{19-22}$ have demonstrated that sagittal balance, rather than coronal balance (CB), is significantly correlated with health-related quality of life (HRQOL). Others have found great impacts of lumbar lordosis (LL) and thoracic kyphosis (TK) on the maintenance and prediction of sagittal balance, which are considered novel regional predictors for sagittal balance. 23,24

The C7 plumb line is the most commonly used index of global balance. This parameter has been historically quantified by measuring the position of a vertical line originating in the center of the $\mathrm{C} 7$ vertebral body with respect to the posterior superior corner of S1. ${ }^{25-27}$ In a systematic literature review, Kuntz et al. ${ }^{28}$ noted that as a global parameter, the $\mathrm{C} 7$ plumb line was a stable, reliable index of sagittal balance, being maintained in narrow ranges for alignment of the spine over the pelvis and femoral heads. Furthermore, the morphology of the pelvis, and the position of the pelvis relative to the spine, may also influence sagittal spinal alignment and balance. ${ }^{29-33}$ Glassman et al. ${ }^{34}$ reported that a positive sagittal balance is related to symptomatology and quality of life in patients with spinal deformities. Berthonnaud et $\mathrm{al}^{2}{ }^{2}$ have proposed the concept of a linear chain linking the head to the pelvis, in which the shape and orientation of each anatomic segment are closely related and influence the adjacent segment to maintain a stable posture with minimum energy expenditure. Accordingly, a change in the shape or orientation of any anatomic segment will modify the shape and/or orientation of adjacent segments of the spine and pelvis. The differences between normal and pathologic curvatures are less clear in the sagittal plane than in the coronal plane. ${ }^{35}$

\section{METHODS}

\section{Population}

The sample was composed by 80 patients. Inclusion criteria were patients with a diagnosis of AIS, a PA, and lateral full-length radiographs. Exclusion criteria were having undergone surgery, having initiated orthotic treatment, and a low quality radiography (without inclusion from $\mathrm{C} 1$ to $\mathrm{S} 1$ and without inclusion of femoral heads or incorrect positioning, mainly of the upper limbs).

\section{Radiography}

All the radiographs were performed in the same hospital and requested by the same doctor. As recommended by the Scoliosis Research Society, plain full-length radiographs were performed in the upright standing position, with the anterior superior iliac spines and hips parallel to the cassette and the beam aimed at T10. Lateral radiographs were performed with the patient in as similar a position as possible to the PA radiograph, with the beam at $90^{\circ}$ to that used for the PA radiography, anterior superior iliac spines and hips perpendicular to the film, and the right side of the patient parallel to the cassette. Both feet were on the same alignment, 20 to $25 \mathrm{~cm}$ between each other, with the fingertips resting on the collarbones.

\section{Parameters}

The parameters evaluated were: age, sex, pelvic incidence, sacral slop, pelvic tilt, global sagittal and coronal balance, sagittal Cobb angle between T1 and T5, and sagittal Cobb angle between T5 and T12. Regarding the parameters evaluated, and their description, the shape of the cervical spine was obtained through the angle between two lines parallel to the posterior margins of the vertebral bodies of C2 and C7 (Jackson physiological stress lines). Thoracic kyphosis was evaluated from the Cobb angle between two lines; one along the upper platform of the body of $\mathrm{T} 1$ and the other along the lower platform of the body of T5 that measured the upper thoracic kyphosis, and two other lines; one along the superior end plate of T5 vertebral body and the other along the inferior end plate of T12 vertebral body (19), which measured the inferior thoracic kyphosis. Lumbar lordosis was assessed through the Cobb angle between a line along the superior L1 end plate and another along the upper sacral plate. Regarding the pelvic parameters, the pelvic incidence is the angle between the perpendicular to the sacral plate and the line connecting the sacral end plate midpoint to the hip axis. The sacral slope is the angle between the superior end plate of S1 and the horizontal plane. The pelvic tilt is the angle between the line connecting the midpoint of the sacral plate to the hip axis and the vertical plane. The sagittal balance is assessed by the horizontal distance or misalignment of a vertical line passing from the center of $\mathrm{C} 7$ vertebral body to the posterolateral part of the S1 superior end plate. It was considered positive vs negative as it presented an anterior vs posterior deviation from the previously stipulated line. To assess coronal balance, a vertical line is drawn downwards from the midpoint of the $\mathrm{C} 7$ vertebral body. The horizontal distance between this plumb line and the midline of the sacrum or central sacral vertical line is measured and the position of this line is then named positive, neutral or negative, depending on the distance and direction from the midline.

\section{Statistical analysis}

SPSS Statistics V21 MacOSX was used to perform this study.

A descriptive statistical analysis of all variables was collected. Subsequently, a separate analysis of the sagittal balance and the remaining variables under study was performed using the Spearman test. The assessment of the difference between the positive vs negative sagittal balance relative to the different variables was obtained through an independent-sample T test (Levene's Test for Equality of Variances and t-test for Equality of Means). The differences between sex were also obtained from this last test.

As this work is retrospective, based solely on imaging study without direct contact with patients, interviews, or application of scores, the hospital where the study was performed does not require approval by the ethics committee. 


\section{RESULTS}

The idiopathic scoliosis group showed a mean age of 12.44 years, a mean sagittal balance of $-1.14 \pm 3.30 \mathrm{~cm}$ and 29 patients with a negative sagittal deviation $(<-2 \mathrm{~cm})$, only 9 with a positive deviation $(>2 \mathrm{~cm})$ and the remainder were considered balanced (with SB greater than $-2 \mathrm{~cm}$ and less than $2 \mathrm{~cm}$ ). The mean coronal balance was $-0.49 \pm 1.34 \mathrm{~cm}$ and LL $58.08 \pm 12.47^{\circ}$. (Table 1)

Thoracic kyphosis presented a mean value between T1-T5 of $19.46 \pm 9.26^{\circ}$ and between T5-T12 of $26.99 \pm 11.13^{\circ}$. (Table 1) The main coronal curvatures had a mean value of $21.83 \pm 15.68^{\circ}$ and were later divided into 3 groups: patients with scoliotic angles of $10-20^{\circ}, 20-45^{\circ}$ and $>45^{\circ}$, each presenting a prevalence of $72.5 \%$, $15.0 \%$ and $12.5 \%$, respectively. Regarding the location of the main curvatures, $32.5 \%$ were thoracic, $53.8 \%$ thoracolumbar and $13.8 \%$ lumbar. The spinopelvic parameters presented mean values similar to those found in previous studies, with a PI of $50.79 \pm 14.31^{\circ}$, an SS of $42.48 \pm 10.51^{\circ}$ and a mean PT of $8.68 \pm 9.94^{\circ}$. (Table 1)

The sagittal Cobb angle of T1-T5 showed a statistically significant $(p<0.05)$ and positive correlation with the sagittal balance, indicating that an increase in the sagittal Cobb angle in the upper portion of the thoracic spine would lead to an increase in sagittal decompensation in a positive direction, which did not occur with the lower portion of the thoracic spine (T5-T12), lumbar lordosis curvature, or other variables. (Table 2) Moreover, a detailed analysis of these two variables showed that AIS patients with negative sagittal balances had a lower kyphotic Cobb angle in both the upper and lower thoracic spine compared to those with positive sagittal balances, although the difference was only significantly higher $(p<0.05)$ in the upper thoracic region (T1 to T5). On the other hand, scoliotic patients with sagittal balance $<2 \mathrm{~cm}$ vs $>/=2 \mathrm{~cm}$ presented, respectively, upper thoracic spine (T1-T5) angles of $18.56 \pm 9.32^{\circ}$ vs $25.78 \pm 6.05^{\circ}$. (Table 3) Regarding the curvature of the cervical spine, $38.8 \%$ of the
AIS patients presented lordotic curvature, 28.8\% were straight, and $23.8 \%$ were kyphotic. Five patients were excluded from the data set in relation to this last variable because they were at the borderline between two cervical shape groups. The data were also crosschecked, to verify whether patients with a positive sagittal balance had spinopelvic parameters, $\mathrm{LL}$, or thoracic sagittal curvature that differed significantly from those with a negative $(<-2 \mathrm{~cm})$ or normal (between $-2 \mathrm{~cm}$ and $2 \mathrm{~cm}$ ) SB. We used an independent sample test (Levene's Test for Equality of Variances and T-test for Equality of Means), which concluded that patients with $\mathrm{SB}>2 \mathrm{~cm}$ presented significantly different Cobb values of the upper thoracic portion (T1 to T5) $(p<0.05)$ and SS $(p<0.05)$ from those of the remaining population (with $\mathrm{SB}<2 \mathrm{~cm}$ ). Using the same test, we verified that scoliotic patients with kyphotic vs lordotic cervical curvatures presented with

Table 3. Differences of AIS patients with sagittal balance $<2 \mathrm{~cm}$ vs $>/=2 \mathrm{~cm}$ regarding thoracic kyphosis, lumbar lordosis and spinopelvic parameters.

\begin{tabular}{c|c|c|c|c}
\hline & SB & Mean & Std. Deviation & Std. Error Mean \\
\hline \multirow{2}{*}{ SC from T1 to T5 } & $>=2.00$ & 25.78 & 6.058 & 2.019 \\
\cline { 2 - 5 } & $<2.00$ & 18.56 & 9.324 & 1.175 \\
\hline \multirow{2}{*}{ SC from T5 to T12 } & $>=2.00$ & 29.33 & 12.659 & 4.220 \\
\cline { 2 - 5 } & $<2.00$ & 26.65 & 10.966 & 1.382 \\
\hline \multirow{3}{*}{$\mathrm{LL}$} & $>=2.00$ & 63.11 & 11.952 & 3.984 \\
\cline { 2 - 5 } & $<2.00$ & 57.37 & 12.474 & 1.572 \\
\hline \multirow{2}{*}{$\mathrm{PI}$} & $>=2.00$ & 59.88 & 15.348 & 5.426 \\
\cline { 2 - 5 } & $<2.00$ & 49.58 & 13.860 & 1.789 \\
\hline \multirow{3}{*}{ SS } & $>=2.00$ & 49.22 & 11.333 & 3.778 \\
\cline { 2 - 5 } & $<2.00$ & 41.53 & 10.128 & 1.266 \\
\hline \multirow{2}{*}{$\mathrm{PT}$} & $>=2.00$ & 9.50 & 8.652 & 3.059 \\
\cline { 2 - 5 } & $<2.00$ & 8.57 & 10.162 & 1.312 \\
\hline
\end{tabular}

SB sagittal balance. SCA sagittal Cobb angle. LL lumbar lordosis. PI pelvic incidence. SS sacral slope. PT pelvic tilt.

Table 1. Descriptive statistics of all numeric variables analyzed.

\begin{tabular}{c|c|c|c|c|c|c|c|c|c|c|c|c}
\hline & Age & SB & CB & CC & SC D1-D5 & SC D5-D12 & LL & LLD & P0 & PI & SS & PT \\
\hline Mean & 12.44 & -1.1412 & -.4914 & 21.83 & 19.46 & 26.99 & 58.08 & .5248 & .5486 & 50.79 & 42.48 & 8.68 \\
\hline Std. Deviation & 2.386 & 3.30729 & 1.34052 & 15.683 & 9.264 & 11.130 & 12.475 & .44322 & .49723 & 14.316 & 10.512 & 9.942 \\
\hline
\end{tabular}

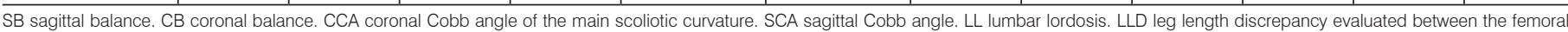
heads. PO pelvic obliquity. PI pelvic incidence. SS sacral slope. PT pelvic tilt.

Table 2. Direct correlations between variables using Pearson Test.

\begin{tabular}{|c|c|c|c|c|c|c|c|c|c|c|c|c|}
\hline & & SB & CB & CCA & SC D1-D5 & SC D5- D12 & LL & LLD & PO & PI & SS & PT \\
\hline \multirow{2}{*}{ SB } & Correlation Coefficient & 1.000 & .107 & -.141 & $.247^{*}$ & .125 & -.139 & -.159 & -.202 & -.014 & .087 & -.077 \\
\hline & Sig. (2-tailed) & & .367 & .235 & .037 & .294 & .245 & .179 & .087 & .911 & .463 & .532 \\
\hline \multirow{2}{*}{$\mathrm{CB}$} & Correlation Coefficient & .107 & 1.000 & -.219 & -.035 & .044 & .050 & .002 & -.197 & .040 & .133 & -.211 \\
\hline & Sig. (2-tailed) & .367 & 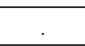 & .054 & .769 & .711 & .675 & .986 & .083 & .746 & .260 & .084 \\
\hline \multirow{2}{*}{ CCA } & Correlation Coefficient & -.141 & -.219 & 1.000 & -.144 & $-.267^{*}$ & -.122 & -.107 & -.107 & .190 & .115 & .130 \\
\hline & Sig. (2-tailed) & .235 & .054 & & .227 & .023 & .307 & .346 & .343 & .121 & .331 & .290 \\
\hline \multirow{2}{*}{ SCA D1-D5 } & Correlation Coefficient & $.247^{*}$ & -.035 & $-.244^{*}$ & 1.000 & .143 & .127 & .000 & .031 & -.069 & -.008 & -.196 \\
\hline & Sig. (2-tailed) & .037 & .769 & .039 & . & .231 & .291 & .998 & .797 & .578 & .949 & .109 \\
\hline \multirow{2}{*}{ SCA D5-D12 } & Correlation Coefficient & .125 & .044 & $-.280^{*}$ & .143 & 1.000 & $.283^{*}$ & .111 & .155 & -.130 & -.061 & -.181 \\
\hline & Sig. (2-tailed) & .294 & .711 & .017 & .231 & & .017 & .352 & .193 & .291 & .612 & .139 \\
\hline \multirow{2}{*}{ LL } & Correlation Coefficient & -.139 & .050 & -.122 & .127 & $.283^{*}$ & 1.000 & .116 & .076 & $.508^{* *}$ & $.754^{* *}$ & -.198 \\
\hline & Sig. (2-tailed) & .245 & .675 & .307 & .291 & .017 & . & .334 & .528 & .000 & .000 & .109 \\
\hline \multirow{2}{*}{ LLD } & Correlation Coefficient & -.159 & .002 & -.107 & .000 & .111 & .116 & 1.000 & $.788^{* *}$ & -.006 & -.087 & .002 \\
\hline & Sig. (2-tailed) & .179 & .986 & .346 & .998 & .352 & .334 & . & .000 & .962 & .466 & .988 \\
\hline \multirow{2}{*}{$\mathrm{PO}$} & Correlation Coefficient & -.202 & -.197 & -.107 & .031 & .155 & .076 & $.788^{* *}$ & 1.000 & -.064 & -.149 & .056 \\
\hline & Sig. (2-tailed) & .087 & .083 & .343 & .797 & .193 & .528 & .000 & . & .607 & .209 & .652 \\
\hline \multirow{2}{*}{$\mathrm{PI}$} & Correlation Coefficient & -.014 & .040 & .190 & -.069 & -.130 & $.508^{* *}$ & -.006 & -.064 & 1.000 & $.691^{* *}$ & $.515^{* *}$ \\
\hline & Sig. (2-tailed) & .911 & .746 & .121 & .578 & .291 & .000 & .962 & .607 & & .000 & .000 \\
\hline \multirow{2}{*}{ SS } & Correlation Coefficient & .087 & .133 & .115 & -.008 & -.061 & $.754^{* *}$ & -.087 & -.149 & $.691^{* *}$ & 1.000 & -.169 \\
\hline & Sig. (2-tailed) & .463 & .260 & .331 & .949 & .612 & .000 & .466 & .209 & .000 & & .167 \\
\hline \multirow{2}{*}{ PT } & Correlation Coefficient & -.077 & -.211 & .130 & -.196 & -.181 & -.198 & .002 & .056 & $.515^{* *}$ & -.169 & 1.000 \\
\hline & Sig. (2-tailed) & .532 & .084 & .290 & .109 & .139 & .109 & .988 & .652 & .000 & .167 & \\
\hline
\end{tabular}

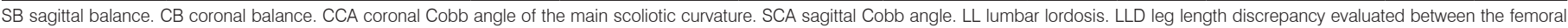
heads. PO pelvic obliquity. PI pelvic incidence. SS sacral slope. PT pelvic tilt. ${ }^{*}$. Correlation is significant at the 0.05 level (2-tailed). ${ }^{* *}$. Correlation is significant at the 0.01 level (2-tailed). 
significantly different SB $(p<0.01),-3.66 \pm 3.15 \mathrm{~cm}$ vs $0.73 \pm 2.24 \mathrm{~cm}$, respectively. (Table 4 and 5 ) This correlation did not occur in the comparison of SB and the remaining variables, including the lower thoracic spine Cobb angle (from T5 to T12) or LL.

The coronal Cobb angle of the main scoliotic curvature showed a significant and inverse correlation with the kyphotic angle of the upper and lower portion of the thoracic spine $(p<0.05)$ (Table 2), demonstrating that an increase in the severity of scoliosis was correlated with an increase in the severity of the hypokyphosis itself. This result is in agreement with previous studies that support the relationship between scoliosis and hypokyphosis. The coronal Cobb angle presented a positive and significant correlation $(p<0.05)$ with $\mathrm{PI}$, as demonstrated by the higher PI values in those with a higher Cobb angle of primary scoliotic curvature. PI did not show a significant correlation with thoracic kyphosis or sagittal balance.

Lumbar lordosis presented a positive and significant correlation $(p<0.05)$ with the lower thoracic spine (T5 to T12), PI and SS, but was not correlated with the remaining variables.

The spinopelvic parameters were strongly related to each other $(p<0.01)$. Interestingly, the coronal balance had no significant correlation with the variables analyzed, including the coronal Cobb angle of the main scoliotic curve. This may have been due to the small discrepancy in the results for CB found in our group.

Table 4. Analysis of sagittal balance between patients with kyphotic cervical shape comparatively to lordotic cervical shape.

\begin{tabular}{c|c|c|c|c|c}
\hline & $\begin{array}{c}\text { Cervical } \\
\text { shape }\end{array}$ & $\mathbf{N}$ & Mean & Std. Deviation & Std. Error Mean \\
\hline \multirow{2}{*}{$\begin{array}{c}\text { Sagittal } \\
\text { balance }\end{array}$} & Kyphotic & 19 & -3.667 & 3.152 & .723 \\
\cline { 2 - 6 } & Lordotic & 31 & .730 & 2.244 & .403 \\
\hline
\end{tabular}

Table 5. Analysis of SB differences between patients with kyphotic cervical shape comparatively to lordotic cervical shape (through Levene's Test for Equality of Variances and T-test for Equality of Means).

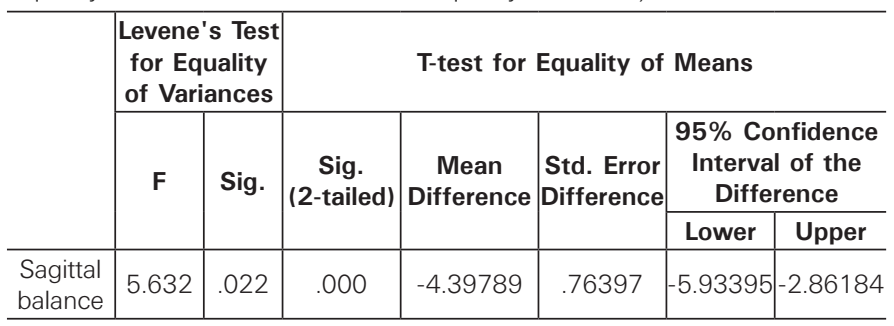

\section{DISCUSSION}

The spine is a complex structure balanced by multiple forces that implement structural changes in an attempt to compensate the sagittal and coronal vertical axis, so that the human being maintains as balanced a movement as possible. Sagittal balance can be maintained through three main compensatory mechanisms, which may occur in the spine, pelvis and/or lower limb areas, including reduction of TK/ hyperextension of adjacent segments, pelvis retroversion (increase of PT and rotation of the pelvis), knee flexion and ankle extension. ${ }^{36,37}$ Hyperextension of the adjacent segments is a common compensatory mechanism in retaining sagittal balance, as pelvis retroversion, knee flexion and ankle extension may occur secondary to hyperextension of the adjacent segments of these are too rigid to extend or reach their limits. ${ }^{36-38}$ Yang $\mathrm{C}$ et al. ${ }^{23,24}$ Also advocated an analogy between LL, TK and sagittal balance. Thoracic hypokyphosis may be a risk factor for scoliosis curve progression based on the theory of "anterior column overgrowth", and the results of histomorphometric and magnetic resonance imaging studies that showed disproportionate growth of the anterior and posterior vertebral columns in patients with idiopathic scoliosis. ${ }^{39,40}$ The progression velocity of scoliosis curves may be greater in patients with thoracic hypokyphosis than in those with normal thoracic kyphosis. ${ }^{41}$ In another study, thoracic kyphosis was not associated with either the severity of scoliosis at the time of diagnosis or with the risk of progression of scoliosis. ${ }^{42}$ Our sample showed that AIS is related to thoracic hypokyphosis, both in its upper and lower portions. On the other hand, the sagittal balance seems to be much more influenced by the upper spine, specifically by the cervical spine shape and by the first 5 thoracic vertebrae. Idiopathic scoliosis correlates with hypokyphosis and a decrease in cervical lordosis, two parameters with a significant and negative influence on SB, which consequently decreases its value in a population with AIS. On the other hand, our results did not present a statistically significant correlation between the sagittal balance and the lumbar lordosis or spinopelvic parameters. This may be because there is no relationship at all between these variables, but it is more likely that the $\mathrm{LL}$ and spinopelvic parameters may have influenced the SB, mainly by indirect mechanisms and compensations, rather than direct ones, which is why they did not reach statistical significance. On the other hand, LL was closely related to the lower portion of the thoracic spine (from T5 to T12) $(p<0.05)$, which did not occur with respect to the upper thoracic portion (from T1 to T5). When evaluating patients with structural deformities of the cervical spine, an in-depth understanding of the spinopelvic parameters is crucial. Pelvic morphology may influence sagittal spinal alignment and balance.43,44

In a well-balanced spine, lumbar lordosis is organized according to SS, which in turn, depends on the shape of the pelvis quantified by the PI. ${ }^{45}$ Mac-Thiong et al. ${ }^{46}$ evaluated the spinopelvic parameters in patients with AIS and concluded that lumbar lordosis was strongly related to the pelvic configuration. Legaya et al. report that $\mathrm{Pl}$ is a fundamental pelvic parameter for the three dimensional regulation of spinal sagittal curves, and is correlated with LL. ${ }^{13}$ In addition, Stagnara et al. ${ }^{35}$ found a strong relationship of lumbar curvature with SS and PT.

In the present sample, LL showed a positive and significant correlation $(p<0.01)$ with $\mathrm{PI}$ and SS and the spinopelvic parameters demonstrated a significant statistical correlation between each other $(p<0.01)$. Thereby, it was possible to confirm a strong connection between the pelvic geometry and lumbar lordosis. On the other hand, the severity of the scoliotic curvature presented a significant direct correlation with the $\mathrm{PI}$, with a tendency to worse scoliotic curvature Cobb angles in patients with higher PI values $(p<0.05)$.

The impact of sex on spinopelvic parameters remains controversial. Vialle et al. reported significant differences in LL and PI between male and female subjects. ${ }^{47}$ In addition, Zhu et al. found a significant sex difference in LL. ${ }^{48}$ Conversely, as in this sample, other researchers did not demonstrate significant sex differences in any spinopelvic parameter. ${ }^{49-51}$

Interestingly, the coronal balance did not correlate with the variables under study, possibly due to the small discrepancy of results found in the main population with idiopathic scoliosis, in relation to this variable.

The results of this study may be of paramount importance in the analysis and planning of the surgical treatment of patients with spinal adolescent idiopathic scoliosis deformity, differentiating some of the most influential parameters in the SB.

\section{CONCLUSIONS}

Based on this study, we can infer several relevant factors that influence sagittal balance. We can also conclude that the spine of a population with AIS presents a series of spinal compensations and mechanisms that lead to structural alterations that directly influence the vertical axis.

Sagittal balance is a parameter that is influenced by multiple factors. In fact, it is closely related to the cervical shape and the upper thoracic spine (from T1 to T5), which in turn, is in symbiosis with the severity of scoliotic curvature. The Cobb angle of the lower portion of the thoracic spine (from T5 to T12) presents a closer relation with the angle of lumbar lordosis than with the upper thoracic curvature (from T1 to T5).

All authors declare no potential conflict of interest related to this article. 
CONTRIBUTION OF THE AUTHORS: Each author made significant individual contributions to this manuscript. EMP (0000-0002-4036-7478), JA (00000002-7468-085X), AT (0000-0002-9617-8473), and AM (0000-0001-7287-7475) certify that each author participated in and contributed sufficiently to the work to take public responsibility for the suitability of the experimental design and method and the collection, analysis and interpretation of the data, and that this final version was reviewed and approved for submission and/or publication. ${ }^{*}$ ORCID (Open Researcher and Contributor ID).

\section{REFERENCES}

1. Pinheiro-Franco JL, Roussouly P. Vaccaro AR. Importância do Equilíbrio Sagital no Tratamento Cirúrgico da Doença Degenerativa Discal Lombar. In: Pinheiro-Franco JL, Vaccaro AR, Benzel EC, Mayer H-M, editors. Conceitos Avançados em Doença Degenerativa Discal Lombar. Rio de Janeiro: DiLivros Publisher; 2010. p. 277-86.

2. Berthonnaud $\mathrm{E}$, Dimnet J, Roussouly $\mathrm{P}$, Labelle $\mathrm{H}$. Analysis of the sagittal balance of the spine and pelvis using shape and orientation parameters. J Spinal Disord. 2005;18(1):40-7.

3. Descamps H, Commare-Nordmann MC, Marty C, Hecquet J, Duval- Beaupère G. Modification of pelvic angle during the human growth [In French]. Biom Hum Anthropol. 1990;17:59-63

4. Duval-Beaupère G, Schimdt C, Cosson P. Abarycentremetric Study of the sagittal shape of spine and pelvis: the conditions required for an economic standing position. Ann Biomed Eng. 1992;20(4):451-62

5. Glassman SD, Berven S, Bridwell K, Horton W, Dimar JR. Correlation of radiographic parameters and clinical symptoms in adult scoliosis. Spine (Phila Pa 1976). 2005;30(6):682-8.

6. Hanson DS, Bridwell KH. Rhee JM, Lenke LG. Correlation of pelvic incidence with low- and high-grade isthmic spondylolisthesis. Spine (Phila Pa 1976). 2002;27(18):2026-9.

7. Ohlen $G$, Aaro $S$, Bylund $P$. The sagittal configuration and mobility of the spine in idiopathic scoliosis. Spine (Phila Pa 1976). 1988;13(4):413-6.

8. Marty C, Boisaubert B, Descamps H, Montigny JP, Hecquet J, Legaye J, et al. The sagittal anatomy of the sacrum among young adults, infants, and spondylolisthesis patients. Eur Spine J. 2002;11(2):119-25.

9. Mangione P, Gomez D, Senegas J. Study of the course of the incidence angle during growth. Eur Spine J. 1997:6:163-7

10. La Maida GA, Zottarelli L, Mineo GV, Misaggi B. Sagittal balance in adolescent idiopathic scoliosis: radiographic study of spinopelvic compensation after surgery. Eur Spine J. 2013;22(Suppl 6):S859- 67.

11. Dubousset J. Three dimensional analysis of the scoliotic deformity. In: Weinstein SL, editor. The Pediatric Spine: Principles and Practice. New York: Raven Press; 1994

12. Hammerberg EM, Wood KB. Sagittal profile of the elderly. J Spinal Disord Tech. 2003;16(1):44-50

13. Legaye J, Duval Beaupère G, Hecquet J, Marty C. Pelvic incidence: a fundamental pelvic parameter for three dimensional regulation of spinal sagittal curves. Eur Spine J. 1998:7(2):99-103.

14. Schwab F, Patel A, Ungar B, Farcy JP, Lafage V. Adult spinal deformity-postoperative standing imbalance: how much can you tolerate? An overview of key parameters in assessing alignment and planning corrective surgery. Spine (Phila Pa 1976). 2010;35(25):2224-31.

15. Mendoza-Lattes S, Ries Z, Gao Y, Weinstein S. Natural history of spinopelvic alignment differs from symptomatic deformity of the spine. Spine (Phila Pa 1976). 2009;35(16):E792-8.

16. Roussouly P, Gollogly S, Berthonnaud E, Labelle H, Weidenbaum M. Sagittal alignment of the spine and pelvis in the presence of L5-S1 isthmic lysis and low grade spondylolisthesis. Spine (Phila Pa 1976). 2006;31(21):2484-90.

17. Mac-Thiong JM, Labelle H, Berthonnaud E, Dimar J, Betz R. Sagittal Alignment of the Spine and Pelvis during Growth. Spine (Phila Pa 1976). 2004:29(15):1642-7.

18. Weinstein SL, Dolan LA, Cheng JCY, Danielsson A, Morcuende JA. Adolescent idiopathic scoliosis. Lancet. 2008:371(9623):1527-37.

19. Schwab F, Ungar B, Blondel B, Buchowski J, Coe J, Deinlein D, et al. Scoliosis Research Society Schwab adult spinal deformity classification: a validation study. Spine (Phila Pa 1976). 2012;37(12):1077-82

20. Lafage V, Schwab F, Patel A, Hawkinson N, Farcy JP. Pelvic tilt and truncal inclination: two key radiographic parameters in the setting of adults with spinal deformity. Spine (Phila $\mathrm{Pa}$ 1976). 2009:34(17):E599-606.

21. La Maida GA, Zottarelli L, Mineo GV, Misaggi B. Sagittal balance in adolescent idiopathic scoliosis: radiographic study of spino-pelvic compensation after surgery. Eur Spine J. 2013:22(Suppl 6):S859-67.

22. Jang JS, Lee SH, Min JH, Kim SK, Han KM, Maeng DH. Surgical treatment of failed back surgery syndrome due to sagittal imbalance. Spine (Phila Pa 1976). 2007;32(26):3081-7.

23. Yang $C$, Yang $M$, Wei $X$, Shao J, Chen $Y$, Zhao J, et al. Lumbar Lordosis Minus Thoracic Kyphosis (LITk): A Novel Regional Predictor for Sagittal Balance in Elderly Populations. Spine (Phila Pa 1976). 2016;41(5):399-403.

24. Yang M, Yang C, Chen Z, Wei X, Chen Y, Zhao J, et al. Lumbar Lordosis Minus Thoracic Kyphosis: Remain Constant in Adolescent Idiopathic Scoliosis Patients Before and After Correction Surgery. Spine (Phila Pa 1976). 2016;41(6):E359-63.

25. Gelb DE, Lenke LG, Bridwell KH, Blenke K, McEnery KW. An analysis of sagittal spinal alignment in 100 asymptomatic middle and older aged volunteers. Spine (Phila Pa 1976). 1995;20(12):1351-8

26. Van Royen BJ, Toussaint HM, Kingma I, Bot SD, Caspers M, Harlaar J, et al. Accuracy of the sagittal vertical axis in a standing lateral radiograph as a measurement of balance in spinal deformities. Eur Spine J. 1998;7(5):408-12

27. Vedantam R, Lenke LG, Bridwell KH, Linville DL, Blanke K. The effect of variation in arm position on sagittal spinal alignment. Spine (Phila Pa 1976). 2000:25(17):2204-9.

28. Kuntz C 4th, Levin LS, Ondra SL, Shaffrey Cl, Morgan CJ. Neutral upright sagittal spinal alignment from the occiput to the pelvis in asymptomatic adults: a review and resynthesis of the literature J Neurosurg Spine. 2007:6(2):104-12

29. Abelin K, Vialle R, Lenoir T, Thévenin-Lemoine C, Damsin JP, Forin V. The sagittal balance of the spine in children and adolescents with osteogenesis imperfecta. Eur Spine J. 2008:17(12):1697-1704

30. Barrey C, Jund J, Noseda O, Roussouly P. Sagittal balance of the pelvis-spine complex and lumbar degenerative diseases. A comparative study about 85 cases. Eur Spine J. 2007:16(9):1459-67.

31. Chanplakorn P, Wongsak S, Woratanarat P, Wajanavisit W, Laohacharoensombat W. Lumbo pelvic alignment on standing lateral radiograph of adult volunteers and the classification in the sagittal alignment of lumbar spine. Eur Spine J. 2011;20(5):706-12.

32. Endo K, Suzuki H, Tanaka H, Kang Y, Yamamoto K. Sagittal spinal alignment in patients with lumbar disc herniation. Eur Spine J. 2009;19(3):435-8.

33. Roussouly P, Nnadi C. Sagittal plane deformity: an overview of interpretation and management. Eur Spine J. 2010:19(11):1824-36.

34. Glassman SD, Bridwell K, Dimar JR, Horton W, Berven S, Schwab F. The impact of positive sagittal balance in adult spinal deformity. Spine (Phila Pa 1976). 2005;30(18):2024-9

35. Stagnara P. DeMauroy JC. Dran G. Gonon GP, Costanzo G, Dimnet J, et al. Reciprocal angulation of vertebral bodies in a sagittal plane: approach to references for the evaluation of kyphosis and lordosis. Spine (Phila Pa 1976). 1982;7(4):335- 42

36. Barrey C, Roussouly P. Perrin G, Le Huec JC. Sagittal balance disorders in severe degenerative spine. Can we identify the compensatory mechanisms? Eur Spine J. 2011;20(Supp 5):626-33

37. Yagi M, Hosogane N, Okada E, Watanabe K, Machida M, Tezuka M, et al. Factors affecting the postoperative progression of thoracic kyphosis in surgically treated adult patients with lumbar degenerative scoliosis. Spine (Phila Pa 1976). 2014;39(8):E521-8.

38. Le Huec JC, Saddiki R, Franke J, Rigal J, Aunoble S. Equilibrium of the human body and the gravity line: the basics. Eur Spine J. 2011;20(Suppl 5):558-63.

39. Guo X, Chau WW, Chan YL, Cheng JC. Relative anterior spinal overgrowth in adolescent idiopathic scoliosis. Results of disproportionate endochondral membranous bone growth. J Bone Joint Surg Br. 2003;85(9):1026-31.

40. Zhu F, Qiu Y, Yeung HY, Lee KM, Cheng JC. Histomorphometric study of the spinal growth plates in idiopathic scoliosis and congenital scoliosis. Pediatr Int. 2006:48(6):591-8.

41. Ylikoski M. Growth and progression of adolescent idiopathic scoliosis in girls. J Pediatr Orthop B. 2005;14(5):320-4.

42. Bunnell WP. The natural history of idiopathic scoliosis before skeletal maturity. Spine (Phila Pa 1976). 1986:11(8):773- 6

43. Jiang J, Qiu Y, Mao S, Zhao Q, Qian B, Zhu F. The influence of elastic orthotic belt on sagittal profile in adolescent idiopathic thoracic scoliosis: a comparative radiographic study with Milwaukee brace. BMC Musculoskelet Disord. 2010;11:219

44. Lazennec JY, Brusson A, Rousseau MA. Hip-spine relations and sagittal balance clinical consequences. Eur Spine J. 2011;20(Suppl 5):686-98.

45. Roussouly P. Pinheiro-Franco JL. Sagittal parameters of the spine: biomechanical approach. Eur Spine J. 2011:20(Suppl 5):S578-85.

46. Mac-Thiong JM, Labelle H, Charlebois M, Huot MP, de Guise JA. Sagittal plane analysis of the spine and pelvis in adolescent idiopathic scoliosis according to the coronal curve type. Spine (Phila Pa 1976). 2003;28(13):1404-9

47. Vialle R, Levassor N, Rillardon L, Templier A, Skalli W, Guigui P. Radiographic analysis of the sagittal alignment and balance of the spine in asymptomatic subjects. J Bone Joint Surg Am. 2005;87(2):260-7

48. Zhu Z, Xu L, Zhu F, Jiang L, Wang Z, Liu Z, et al. Sagittal alignment of spine and pelvis in asymptomatic adults: norms in Chinese populations. Spine (Phila Pa 1976). 2014:39(1):E1-6.

49. Mac-Thiong JM, Roussouly P, Berthonnaud E, Guigui P. Age and sex related variations in sagittal sacropelvic morphology and balance in asymptomatic adults. Eur Spine J. 2011:20(Suppl 5):572-7.

50. Lee CS, Chung SS, Kang KC, Park SJ, Shin SK. Normal patterns of sagittal alignment of the spine in young adults radiological analysis in a Korean population. Spine (Phila Pa 1976). 2011:36:E1648-54.

51. Janssen MM, Drevelle X, Humbert L, Skalli W, Castelein RM. Differences in male and female spino-pelvic alignment in asymptomatic young adults: a three-dimensional analysis using upright low-dose digital biplanar X-rays. Spine (Phila Pa 1976). 2009:34:E826-32 